\title{
UMA FANTASMA NA LITERATURA JUVENIL BRASILEIRA: ENTRE LADRILHOS E ASSOMBROS
}

\author{
Andréia de Oliveira Alencar Iguma \\ Doutoranda em Letras pela Universidade Federal de Uberlândia (UFU) \\ Professora do Centro Universitário da Grande Dourados \\ dheia_oliveira@hotmail.com
}

\section{RESUMO}

O presente artigo nasce com o objetivo de pensar acerca da produção contemporânea entendida como literatura juvenil. Para tanto, foi selecionada a narrativa A bailarina fantasma (2009), escrita por Socorro Acioli, selecionada pelo Programa Nacional Biblioteca da Escola - PNBE - na versão do ano de 2010. Para tanto, o caminho a ser traçado se dividi em dois momentos: o primeiro conduzirá a reflexões que circunscrevem o sistema da literatura juvenil brasileira contemporânea, uma vez que os estudos nessa área ainda são recentes; teremos como apoio teórico a contribuição de Ceccantini (2010), pioneiro da referida área e a leitura de artigos e teses que contemplem a temática. Na sequência, analisaremos a narrativa supracitada a luz da teoria fantástica pela perspectiva modal; é importante ressaltar que a presença insólita é expressiva dentro dessa produção, e, ainda, é pouco estudada no que tange os estudos dentro da produção literária infantil e juvenil. Para esse momento contaremos com o apoio de Bessière (2013), Ceserani (2006), Gama-Khalil (2013), entre outros.

Palavras-chave: insólito, literatura juvenil, PNBE.

\section{ABSTRACT}

This article is born with the objective of thinking about the production contemporary as juvenile literature. For that, the narrative $A$ bailarina fantasma (2009), written by Socorro Acioli, selected by the Programa Nacional Biblioteca da Escola - PNBE - in the version of the year 2010. For this the path to be divided into two moments: the first will lead to reflections that circumscribe the subsystem of the contemporary brazilian youth literature, since studies in this area are still recent; we will have as theoretical support the contribution of Ceccantini (2010), pioneer of this area and the reading of articles and theses that contemplate the theme. Following, we will analyze the narrative aforecited the light of fantastic theory by the modal perspective; it is important to emphasize that the unusual presence is expressive within this production, and, still, it is little studied in what studies within the literary production of children and adolescents. For this moment we will tell with the support of Bessière (2013), Ceserani (2006), Gama-Khalil (2013), Roas (2014), among others.

Keywords: unusual, youth literature, PNBE. 


\section{Introdução}

"A literatura nos permite viver num mundo onde as regras inflexíveis da vida real podem ser quebradas, onde nos libertamos do cárcere do tempo e do espaço, onde podemos cometer excessos sem castigo e desfrutar de uma soberania sem limites." (LLOSA, Mário Vargas).

A epígrafe que inaugura nossa escrita traz em seu bojo a dupla "tarefa" da literatura, posto que, ao mesmo tempo em que sua presença nos incomoda, machuca e nos expulsa de nossa zona de conforto, também nos transpõe para outros mundos, quebrando as algemas da dolorosa realidade ao propiciar a vivência de uma das mais profundas buscas humanas: a liberdade.

Essa suposta liberdade apregoada em um sistema regido "democraticamente" é totalmente questionável em diferentes esferas da nossa sociedade, uma vez que somos censurados, vigiados e punidos, lembrando aqui de Michel Foucault. E essa prisão disfarçada integra nossa construção desde a idade mais tenra, afinal, a criança já nasce sendo descaracterizada por meio da aprendizagem da "moral e bons costumes"; e com a inserção no ambiente escolar a coerção expande, uma vez que as escolas, em sua maioria, obedecem às regras de sistemas carcerários, com suas grades metafóricas.

A composição da estrutura curricular é cansativa, repetitiva e desestimulante; assim, pouco tempo é investido na construção do pensamento crítico. As disciplinas das humanas perdem cada vez mais visibilidade e as bibliotecas escolares dividem espaços ou se tornam depósitos, o que dificulta a vivência entre alunos e livros. E, para agravar ainda mais a problemática, o Programa Nacional Biblioteca da Escola - PNBE, que foi responsável por abastecer as bibliotecas escolares públicas desde 1997, foi suspenso sem 
justificativas plausíveis, repetindo a história dos seus antecessores, o que contribuiu no processo contrário da formação de leitores, haja vista que muitas das crianças e adolescentes do nosso país só terão acesso a obras com qualidade estética, como $A$ bailarina Fantasma (2009), escrita por Socorro Acioli, que foi comprada pelo programa, no âmbito escolar.

Diante do exposto, é importante trazer à baila a forte relação entre a literatura adjetivada como juvenil e o sistema escolar, pois, para muitos, a literatura juvenil é um sistema menor, posto que está atrelada ao didático e não ao estético. Tal problemática é consequência do surgimento da literatura infantil em terras brasileiras, não como arte, mas como instrumento de moralismo, didatismo, a fim de difundir "ideias" de um país que estaria em transição do Império para a República, objetivando "vender" a imagem de um Brasil em progresso.

Desse modo, nos compete para este estudo averiguar, mesmo que de maneira breve, a gênese da literatura juvenil, especificamente no Brasil, e validar a importância em fomentar estudos na área. Feito isso, analisaremos a obra literária $A$ bailarina fantasma (2009) que integra a composição do acervo do PNBE. A referida obra foi eleita como nosso corpus porque ao fazermos uma busca nos centros de referências da crítica literária percebemos que ela foi pouco estudada. Ademais, por ter sido adquirida com verba pública para as escolas brasileiras, acreditamos que o trabalho analítico seja importante a fim de contribuir com o trabalho de professores que a tenham como objeto de trabalho. Por fim, entendemos que ainda há uma lacuna no que tange aos trabalhos teóricos com narrativas insólitas dentro da produção juvenil. 


\section{Literatura juvenil contemporânea: entre nós e laços}

Clarice não tinha segredos com ele, nem Jarbas com Clarice, eram também como a mão esquerda e a direita, cada um vivendo de um jeito diferente e estranhamente tão iguais. Ele também adorava ler, porém gostava mais do Caio Fernando de Abreu, que morreu de Aids, ou da Ana Cristina César, que se suicidou, do que de Clarice Lispector que simplesmente morreu. Clarice, a escritora, quase fazia parte da sua trupe de escritores preferidos, mas não ficava na estante mais acessível, nem mesmo na terceira prateleira onde ele deixava os livros para ler nos dias nublados, quando se emocionava vivendo dentro das histórias e dos pensamentos do autor (MARINHO, 2005, p. 57 - grifos nossos).

O excerto acima integra a narrativa Lis no peito: um livro que pede perdão (2005), de autoria de Jorge Miguel Marinho, que recebeu com a referida obra prêmios importantes, tais como o Prêmio livro juvenil Lessa/FNLIJ - melhor livro juvenil no ano de 2006; Prêmio Jabuti/CBL - melhor livro juvenil do ano 2006 (projeto gráfico); White Ravens - Biblioteca de Munique 2006. Foi também comprada com verba pública por meio do PNBE - versão 2009 -, a fim de integrar as bibliotecas escolares brasileiras.

$\mathrm{Na}$ referida citação conseguimos vislumbrar pontos cruciais que encaminham a produção entendida como LJ. Temos duas personagens, Clarice e Jarbas. Ambas são cúmplices e leitoras com peculiaridades, mas "estranhamente tão iguais" (2005). Entre as supostas diferenças é possível perceber a predileção pelos autores literários. Enquanto Jarbas era leitor assíduo de Caio Fernando de Abreu e Ana Cristina César, Clarice era leitora da outra Clarice, a Lispector. Poderíamos conjecturar que os elementos que encaminham para a percepção enquanto LJ finalizassem nessa breve introdução; porém, as questões presentes são bem maiores e complexas, posto que diversos assuntos 
presentes na construção identitária do jovem na transição criança - adulto ganham destaque.

Suicídio, Aids e especialmente a própria morte são considerados por muitos como temas fraturantes e, por isso, excluídos dos bancos escolares e das discussões mediadas entre adultos e jovens. Infelizmente, considerá-los como tabus é um desserviço a favor da construção humana das crianças e/ou adolescentes, haja vista que é fundamental que esses possam ser levados a refletir sobre a vida que "rasga" desde a idade mais tenra. Infelizmente, esse distanciamento de diversos sentimentos impede de conseguirem associar o que sentem e, muitas vezes, desconhecem, pois são afastados de vivências profundas e humanas. Para muitos responsáveis e sistemas escolares, as obras literárias devem ser reduzidas ao fácil e raso, impedindo que a arte, de fato, seja integrada em suas vidas. Na contemporaneidade, muitas obras têm ultrapassado essas barreiras e estão fazendo parte das compras governamentais, como, por exemplo, A bailarina Fantasma (2009), eleita como objeto de análise justamente por trazer em suas páginas a morte elemento importante e que precisa ser olhado de perto. Acreditamos que, na produção contemporânea da $L$, esse quadro vem mudando significativamente e é justamente nesse ponto que começamos a desfazer os nós e a transformá-los em laços.

Após um árduo e longo percurso "os estudos de literatura infantil i estão solidamente estabelecidos na educação superior e na cultura em geral, apesar de ainda serem marginalizados pelos teóricos, em especial os que bradam apoiar os excluídos" (HUNT, 2010, p. 13). O escritor britânico Peter Hunt é responsável por uma sólida contribuição teórica e crítica acerca da literatura infantil. Seu livro é um dos poucos estrangeiros que chegaram traduzidos em solo brasileiro; e infelizmente, produções significativas da Alemanha, Grã-Bretanha, França, Estados Unidos, entre outros países, 
ainda estão longe do nosso alcance. Destarte, no livro Crítica, teoria e literatura infantil (2010) é possível vislumbrarmos que o espaço galgado pela literatura infantil alcançou um lugar sólido e fértil, o que tem possibilitado que estudiosos de diferentes partes do mundo e de áreas plurais, como Psicologia, Letras, Educação e Sociologia empreguem suas pesquisas a fim de examinarem as produções que nascem sob a rubrica infantil e toda a complexidade e diversidade presente nesse arcabouço.

Indubitavelmente, mesmo com lugar consolidado dentro da academia, a referida literatura ainda é alvo de críticas negativas e, tal como ressalta Hunt, tida como inferior pelos estudiosos que ainda habitam as "torres de marfim". Todavia, se a literatura infantil já alcançou seu "lugar ao sol", a LJ, nosso escopo de trabalho, ainda luta por uma legitimação, uma vez que os estudos que engendram sua produção são recentes. Nas palavras do especialista brasileiro João Luís C. T. Ceccantini (2010, p. 82):

[...] é ainda bastante provisória a busca de sentidos para essa produção literária peculiar, em princípio voltada à faixa de leitores que, a partir do início do século XX, constitui esse terreno vago, impreciso e mítico que tem sido denominado "adolescência", na medida em que ainda não possuímos um objeto claramente delimitado e uma metodologia plenamente estabelecida para sua abordagem.

O autor é considerado como pioneiro nos estudos que tangem à LJ a partir da escrita de sua tese de doutoramento: "Uma estética da formação: vinte anos de Literatura Juvenil Brasileira premiada (1978-1997)", produção que tem norteado diversas pesquisas da área, inclusive a nossa. O referido trabalho é um divisor de águas nos estudos acerca das produções juvenis, uma vez que, até então, não havia, no âmbito desses estudos, uma separação entre literatura infantil e juvenil. Com isso, grande parte 
da produção era rotulada como literatura infantojuvenil, termo genérico, ao classificar como similar, o que de fato, é diferente.

No caso brasileiro, a consolidação da literatura juvenil como gênero razoavelmente autônomo - em oposição à literatura infantil - deu-se por volta de meados da década de 70 , quando passa a contar com um conjunto relevante de autores e de obras associados especificamente a um público leitor jovem e ocorre a legitimação do campo por instituições literárias que concedem prêmios na modalidade literatura juvenil ou se voltam à produção regular de pesquisa na área (CECCANTINI, 2010, p. 80).

Dentre aos prêmios concedidos à categoria, damos destaque ao notável trabalho realizado por meio da Fundação Nacional do Livro e da Literatura Infantil e Juvenil - FNLIJ que nasceu na década de 1970, e tem se mantido, como referência no campo literário infantil e juvenil. A princípio (1976) sua premiação contemplava apenas a categoria infância. Porém, em questão de três anos (1976) expandiu para criança e jovem, ambas visavam a produção nacional. No ano de 1989, começou a vislumbrar outras terras e, além das categorias supracitadas, inseriu a categoria Tradução Jovem, que premia obras juvenis traduzidas. Foi em 1994 que a fundação inseriu a categoria Hons Concours - fora da competição, espaço que premia autores e obras que não se inscreveram, mas que, pela sua produção notória, foram reconhecidos. Aqui, damos destaque a três grandes nomes laureados com o prêmio: Bartolomeu Campos de Queirós, Marina Colasanti e Lygia Bojunga.

Com efeito, o arcabouço de obras que integra a minuciosa seleção feita por meio dos avaliadores da FNLIJ traz em suas páginas "representações do jovem que se vê sob as coerções de culturas diferentes daquela por ele vivenciada no interior de sua casa e de sua família, em sociedades que vivem intensas transformações sociais" (CECCANTINI, 
2010, p. 81). No entanto, para que essa pluralidade aconteça, de fato, é imprescindível que diferentes temas sejam contemplados, por meio de gêneros textuais diversificados, a favor de atingir a pluralidade de leitores que povoam este vasto mundo de Raimundo. Nesse prisma, a citação que segue traz, de maneira simplificada, os temas identificados por Ceccantini (2010, p. 82 - grifos nossos) na produção de ப:

\begin{abstract}
A oposição entre os valores de uma sociedade rural e agrária e o mundo urbano e industrializado; a visão mítica de mundo e uma a oposição entre os perspectiva racionalista da realidade; o dado local e o cosmopolita; as identidades nacionais e o fenômeno da globalização; o confronto entre a postura etnocêntrica e intolerante e o reconhecimento do espaço social do outro e a aceitação dos sujeitos, da alteridade e da diferença; o embate entre os papéis masculinos típicos de sociedades patriarcais e o lugar social da mulher no mundo contemporâneo; os variados processos de exclusão social; a oposição entre centro e periferia; as múltiplas identidades sexuais, étnicas, culturais; o poder dos adultos em contraste ao poder dos jovens.
\end{abstract}

A parte em destaque é o chamariz da nossa análise, uma vez que essa oposição da visão mítica à perspectiva racionalista é bem mais complexa que "a vã filosofia dos homens possa imaginar". Entendemos que esse espaço de quebra com a realidade é reservado a grandes rupturas no que tange à ordem preestabelecida pela sociedade. De fato, o jovem, nosso leitor em potencial ainda está em processo de construção identitária e, tantas vezes, por valores religiosos, culturais e/ou morais, experiências são negadas a sua vivência. É justamente ao experimentar esses espaços lisos, de desordem (DELEUZE; GUATTARI, 1997), que eles terão a oportunidade de questionar os espaços estriados, entendidos como a ordem instaurada. Vamos à obra. 


\section{A linha tênue entre o real e o fantástico}

O fantástico instaura a desrazão na medida em que ultrapassa a ordem e a desordem e que o homem percebe a natureza e a sobrenatureza como marcas de uma racionalidade formal (BESSIÈRE, 2012, p. 307).

Ao lermos a palavra fantasma dentro do universo literário, fizemos associações livres ao clássico O fantasma da ópera, de Gaston Leroux, traduzido para diversos idiomas, adaptado para o cinema e consagrado enquanto musical pela Broadway. Ao adentrarmos na narrativa evocada, possivelmente, perceberemos que a linha que separa o real e o fantástico é tênue, uma vez que a obra é tão envolvente, que no decorrer da leitura não paramos mais para questionar o suposto real do suposto imaginário; apenas imergimos.

Mas, de fato, o que seria o fantástico? Por que a presença desse recurso estético é tão peculiar para o nosso crescimento? Pois bem, para refletirmos acerca, evocamos a voz de David Roas (2014, p. 75), conceituado estudioso, ao pontuar que "a imensa maioria das teorias sobre o fantástico define a categoria a partir da confrontação entre duas instâncias fundamentais: o real e o impossível (ou seus sinônimos: sobrenatural, irreal, anormal etc.)". E o que seria o impossível?

Nas palavras de Roas (2014, p. 76) "aquilo que não pode ser, que não pode acontecer", que é inexplicável de acordo com tal concepção. Desse modo, ao adentrarmos a narrativa em evidência em nosso estudo A bailarina fantasma (2009), nos depararemos com presenças fantásticas a todo instante, uma vez que, Anabela, a 
protagonista, tem encontros frequentes com Clara, a bailarina fantasma que mora no teatro José de Alencar.

A especialista Irene Bessière escreve que

o relato fantástico provoca a incerteza ao exame intelectual, pois coloca em ação dados contraditórios, reunidos segundo uma coerência e uma complementaridade próprias. Ele não define uma qualidade atual de objetos ou de seres existentes, nem constitui uma categoria ou um gênero literário, mas supõe uma lógica narrativa que é tanto formal quanto temática e que, surpreendente ou arbitrária para o leitor, reflete, sob o jogo aparente da invenção pura, as metamorfoses culturais da razão e do imaginário coletivo (BESSIÈRE, 2012, p. 305).

A trama tem como espaço a cidade de Fortaleza, Ceará. "Anabela e o pai, Marcelo, tinham orgulho de dizer que moravam na casa mais antiga da cidade, a Travessa do Anjo, uma ilha feita de passado no meio de um mar de vidro e metal" (ACIOLI, 2009, p. 20). Por meio da citação em evidência destacamos a relação entre filha e pai, uma vez que a mãe da personagem principal havia falecido e, desse modo, a menina morava somente com o pai, que era arquiteto especializado em arte clássica e, por isso, conquistou a vaga para a restauração do teatro, cenário da narrativa.

Marcelo era um cara muito legal. Absolutamente apaixonado por sua profissão, a arquitetura, e um dos maiores especialistas em construções do século XIX e XX. A boa notícia daquele dia era que finalmente ele tinha sido contratado como um dos responsáveis pela reforma do Theatro José de Alencar, o mais antigo da cidade de Fortaleza começou a ser construído em 1908 (ACIOLI, 2009, p. 27).

As outras personagens que integram a narrativa são: Luciana, melhor amiga de Anabela; Clara, a bailarina fantasma; Joseph MacFarlane, pai de Clara; Maria Rosa, mãe 
de Clara; Elisabeth MacFarlane, avó paterna de Clara; Carlotta MacFarlane, tia de Clara; Gabriel, namorado de Clara; Dr. Augusto Arruda, pai de Gabriel; Clarisse, filha de Claraii.

Pois bem, voltemos à obra e aos elementos fantásticos, escopo da nossa discussão:

Anabela pensava que a morte era uma cortina pesada e escura, como um veludo vermelho, que só poderia ser aberta para quem passasse daqui para lá. Mas houve um dia que mudou sua vida, quando ela compreendeu de forma definitiva que essa cortina podia ser leve e clara como seda azul e que, com um sopro do vento, ela podia se abrir e dar passagem a alguém vindo de lá... para cá (ACIOLI, 2009, p. 23 - grifos nossos).

A morte, destacada pela nossa leitura, será presença "viva" durante toda a narrativa. E ela ganha maior relevância, pois como trazido no subitem que antecede, por muito tempo, foi considerado tema tabu, praticamente interditado para crianças e jovens. Sua construção no imaginário coletivo é atribuída a algo negativo e tantas vezes silenciado; todavia, sua presença no âmbito artístico contribui para a desconstrução de estereótipos instaurados.

Para a estudiosa Marisa Martins Gama-Khalil (2010, p. 120) “As interpenetrações entre sonho e realidade são constantes e especulares, de forma a gerar um espaço não somente engendrado pelo insólito, mas também um espaço de reflexão sobre as fronteiras entre sonho e realidade e, especialmente, entre vida e morte". Essa fronteira, proposta pela especialista é enxergada na divisão tênue entre o "real" e o fantástico.

Nesse prisma, Ceserani (2006, p. 73) pontua que

várias vezes encontramos [...] exemplos da dimensão do cotidiano, do familiar e do costumeiro para a do inexplicável e do perturbador: 
passagem de limite, por exemplo, da dimensão da realidade para a do sonho, do pesadelo, ou da loucura. O personagem protagonista se encontra repentinamente como se estivesse dentro de duas dimensões diversas, com códigos diversos à sua disposição para orientar-se e compreender.

A escrita de Ceserani (2006) vem ao encontro da nossa ânsia ao ler a obra supracitada, uma vez que o limiar entre o real e o fantástico é frequente. No entanto, esse, de maneira estranha, provavelmente não perturba o leitor, o que nos conduz à compreensão da forte presença do insólito. Anabela habita as duas dimensões trazidas na citação que antecede, e tem a possibilidade de viver em dois mundos. Nesse ponto, chegamos ao coração do nosso estudo, posto que a vida de um jovem nunca é construída apenas no suposto mundo real; pelo contrário. Esse sai, mesmo que psicologicamente, de seu habitat "natural" em busca de outras experiências necessárias para sua construção enquanto sujeito. Ademais, sua mente é povoada por fantasias que conduzem sua sobrevivência no mundo paralelo que constrói, local de liberdade, pois "ali" se vê livre das obrigações introduzidas por meio dos responsáveis legais de sua existência autorizada.

Marisa Gama-Khalil (2013, p. 125) contribui com a nossa construção de sentido ao validar que "o insólito surgia para explicar o sólido; o irreal abria-se como uma zona possível dentro do real, ou, dito de outra forma, o irreal apontava as inconsistências do real". Gama-Khalil (2013, p. 130) argumenta ainda que "a fronteira desencadeia o "efeito limite", e, ao trabalhar com esse efeito, a narrativa desloca posições e sugere o movimento entre ordem e desordem [...] o espaço proposto pela literatura fantástica é o entrelugar, o da indiscernabilidade".

Esse entrelugar pode ser pensado como um limbo. Uma zona fronteiriça entre dois planos habitáveis e desconhecidos. E por que fazemos tal associação? Meio do 
desordenado a ordem é questionada; essa "ordem e desordem" proposta por GamaKhalil pode ser vista claramente na citação que segue:

Os convidados que chegavam para o balé entravam retocando o cabelo ou conversando sobre a rotina do dia. Sem nenhuma admiração, nenhuma descoberta, nenhum espanto [...] As bailarinas conseguiam dançar com tanta leveza que pareciam flutuar. Havia um pouco de fumaça no palco. As luzes, a música, a bruma de gelo-seco... era mágico. Em meio a tudo isso, o olhar de Anabela foi atraído por uma bailarina com tutu azul entre as outras, todas de branco, das sapatilhas aos arranjos do cabelo (ACIOLI, 2009, p. 33 e 39).

Anabela tem seu primeiro encontro com Clara a partir de uma apresentação de

balé. A princípio, nossa protagonista não tinha dimensão do que estava acontecendo. De fato, o estranhamento ocorrido limitou-se ao fato de Clara estar com uma roupa diferente de todo o corpo do balé.

A ficção fantástica fabrica assim outro mundo por meio de palavras, pensamentos e realidade, que são deste mundo. Esse novo universo elaborado na trama do relato se lê entre as linhas e os termos, no jogo das imagens e das crenças, da lógica e dos afetos, contraditórios e comumente recebidos (BESSIÈRE, 2012, p. 304).

Em consonância,

a literatura fantástica não descarta, de maneira alguma, a crítica sobre o real, porém ela encaminha a irrupção da crítica por outra perspectiva. Nela, temos a possibilidade de, diante das ambiguidades deflagradas e pela mistura de mundos e espaços, repensarmos a nossa realidade, aparentemente tão homogênea e ordenada (GAMA-KHALIL, 2013, p. 125). 
A reflexão acurada por meio de Gama-Khalil é de grande relevância a fim de pensarmos o insólito, pois nos encaminha a compreensão de que esse limiar entre o real e o fantástico não é ingênuo, pelo contrário, é responsável por uma crítica forte que nos põe a (re)pensar acerca da nossa realidade, "homogênea e ordenada" tal como posto pela autora.

Na narrativa em evidência nos deparamos com uma cena relevante que retrata o romper do limiar entre o absurdo e o real, pois a personagem "fantasma" consegue ser vista por Anabela, o que contribui para o desenrolar de toda a narrativa:

A bailarina olhou para ela, olhou para trás, como se quisesse ter certeza de que aquela menina, a Anabela, estava de fato concentrada em sua coreografia. Da mesma forma, Anabela olhou para trás e, quando virou de volta, a bailarina estava bem na sua frente, assustadoramente branca, quase transparente, olhando nos olhos de Anabela e perguntando desesperada, repetidas vezes, com seu hálito gelado:

- Você me vê? Você me vê? (ACIOLI, 2009, p. 39).

Nesse entrave, temos o encontro entre os dois universos. Clara fica totalmente assombrada ao perceber que está sendo vista por Anabela; Anabela, ainda não se deu conta de que está conseguindo enxergar um ser de um "outro mundo".

Clara foi assassinada em sua juventude dentro do teatro, no entanto, nunca conseguiu se libertar da vida terrena, pois guardava consigo um segredo de extrema relevância: a vida de uma filha; por isso, precisava de alguém para contar o ocorrido ao pai da criança. Todavia, suas tentativas haviam sido frustradas, porque todas as vezes que estabelecia um contato com alguém, essa pessoa se assustava e não permitia um novo diálogo. Porém, com Anabela, esse estranhamento não gerou empecilho e, desse modo, Clara enxergou em Anabela a grande possibilidade de sua liberdade. 
Anabela aceita o desafio de contribuir com o desfecho da história de Clara. No entanto, a tarefa seria árdua, pois precisaria de ajuda de outras pessoas que dificilmente compreenderiam a complexidade da situação em questão.

Decepção. A resposta não foi tão simples quanto a minha avó me explicará. Ao invés de desatar um nó, eu começava a puxar o fio de um novelo.

A mão branca e fria daquela moça do outro mundo apontou para a parte de baixo do baú, onde havia um fundo falso que escondia a chave dele. Não foi por acaso, não. Ela sabia exatamente onde a chave estava (ACIOLI, 2009, p. 66).

A citação acima nos encaminha a um ponto determinante, posto que temos o contato evidente entre o fantástico e o real. Ademais, a protagonista explicita: "Não aguento mais isso tudo, nem sei mais o que é real. Como é que eu vou chegar na casa de um homem que nunca vi e dizer que um fantasma me mandou entregar uma carta que eu nem posso ler?" (ACIOLI, 2009, p. 148). Exatamente nesse momento conseguimos vislumbrar a ligação entre o fantástico e o real, uma vez que temos o contato com personagens que habitam planos diferentes, e, por conseguinte, possuem algo em comum: uma carta, objeto real e palpável que consegue ser vista por ambas, e que se torna o grande divisor de águas, pois é a partir dela que o desfecho do grande segredo pode vir à tona, o que seria, nas palavras de Roas (2014, p. 80) o encontro entre "limites intransponíveis".

Senhor Gabriel Arruda,

Tenho em minhas mãos uma carta escrita por Maria Rosa MacFarlane endereçada ao senhor. A pessoa que me pediu para vir até aqui me disse que, caso o senhor não acreditasse, dissesse que ela sente muitas saudades de deixar cartas na letra A do letreiro do Theatro José de Alencar. 
Atenciosamente,

Anabela (ACIOLI, 2009, p. 162).

\section{Considerações finais}

"Esse é o grande efeito do fantástico: provocar - e, portanto, refletir - a incerteza na percepção do real"' (ROAS, 2014, p. 111).

A literatura fantástica rompe com o real estático, como trouxemos no corpo do nosso trabalho por meio da reflexão instaurada pela Gama-Khallil. É justamente esse ponto que nos conduz a direcionar o nosso olhar a esse campo de investigação, posto que, tal como Roas propõe na epígrafe das nossas considerações finais, o efeito do fantástico é "provocar - e, portanto, refletir".

A bailarina fantasma (2009) - narrativa eleita para conduzir nossas reflexões neste artigo caminha entre o suposto mundo real e o mundo fantástico e nos leva a indagar acerca dos limiares entre esses dois mundos. De fato, os elementos insólitos são responsáveis pelo ampliar da perspectiva do leitor e são, ainda, esses mesmos elementos que ampliam o horizonte de perspectiva, pois a realidade "crua" limitaria o desvendar dos pontos em evidências abarcados pela autora.

Acrescentamos, ainda, que em se tratando de uma literatura rotulada como juvenil, é importante pensar que esse leitor está em processo de amadurecimento e que muitos dos seus questionamentos escapam às respostas engessadas e formatadas pelo sistema. Nesse sentido, é de grande relevância refletir sobre as "incertezas do real", objetivando um romper com o predeterminado. 


\section{Referências}

ACIOLI, Socorro. A bailarina fantasma. São Paulo: Biruta, 2009.

BESSIÈRE, Irène. O relato fantástico: forma mista do caso e da adivinha. Revista FronteiraZ, São Paulo, n. 9, dez. 2012.

CECCANTINI, João Luís C. T. Conflito de gerações, conflito de culturas: um estudo de personagens em narrativas juvenis brasileiras e galegas. Letras de Hoje, Porto Alegre, v. 45, n. 3, jul-set 2010, p. 80-85.

CESERANI, Remo. O fantástico. Tradução Nilton Tripadalli. Curitiba: Ed. UFPR, 2006.

DELEUZE, Gilles; GUATTARI, Félix. Mil platôs: capitalismo e esquizofrenia Tradução Peter Pál Pelbart e Janice Caiafa. Rio de Janeiro: Editora 34, 1997. v. 5.

GAMA-KHALIL, Marisa Martins; ANDRADRE, Paulo Fonseca (orgs.). As literaturas infantil e juvenil... ainda uma vez. Uberlândia: Gpea: Capes, 2013.

HUNT, Peter. Crítica, teoria e literatura infantil. Tradução Cid Knipel. São Paulo: Cosac Naify, 2010.

LUFT, Gabriela. A literatura juvenil brasileira no início do século XXI: autores, obras e tendências. Estudos de Literatura Brasileira Contemporânea, n. 36. Brasília, jul-dez 2010, p. $111-130$.

MARINHO, Jorge Miguel. Lis no peito: um livro que pede perdão. São Paulo: Biruta, 2005.

MARTHA, Alice Áurea Pentheado. A narrativa juvenil brasileira contemporânea: do mercado às instâncias de legitimação. Guarapuava, v. 2, n. 2, dezembro de 2011, p. 12 21.

PAIVA, Aparecida (org.). Literatura fora da caixa: o PNBE na escola - distribuição, circulação e leitura. São Paulo: Editora Unesp, 2012.

PERRONE-MOISÉS, Leyla. Mutações da literatura no século XXI. São Paulo: Companhia das Letras, 2016.

ROAS, David. A ameaça do fantástico: aproximações teóricas. São Paulo: Editora Unesp, 2014. 


\footnotetext{
' Pesquisas pioneiras acerca da literatura infantil brasileira: História da literatura infantil (1959), de Nazira Salem; Literatura infantil brasileira: ensaio de preliminares para a sua história e suas fontes (1968), de Leonardo Arroyo; A literatura infantil (1981) [desdobrado, a partir de 1984, em dois volumes, dos quais um é o Panorama histórico da literatura infantil/juvenil], de Nelly Novaes Coelho; Literatura infantil brasileira: história \& histórias (1984) e Um Brasil para crianças (1986), ambos de Marisa Lajolo e Regina Zilberman; e Como e por que ler a literatura infantil brasileira (2005), de Regina Zilberman.

ii No presente artigo não analisaremos todas as personagens, uma vez que nosso objetivo é apresentar a relação insólita presente na narrativa por meio do diálogo entre Anabela e Clara.
} 